Article

\title{
Development of the Structure of Cemented Carbides during Their Processing by SLM and HIP
}

\author{
David Bricín ${ }^{1, *}{ }^{\oplus}$, Michal Ackermann ${ }^{2}{ }^{\oplus}$, Zdeněk Jansa ${ }^{3}$, Dana Kubátová ${ }^{4}$, Antonín Kříž ${ }^{1}$, \\ Zbyněk Špirit ${ }^{1}$ and Jiří Šafka ${ }^{2}$ (1) \\ 1 Department of Material Science and Technology, University of West Bohemia, Univerzitni 8, \\ 30100 Pilsen, Czech Republic; kriz@kmm.zcu.cz (A.K.); spirit@kmm.zcu.cz (Z.Š.) \\ 2 Department of Industrial Technology, Technical University of Liberec, Studentská 1402/2, \\ 46117 Liberec, Czech Republic; michal.ackermann@tul.cz (M.A.); jiri.safka@tul.cz (J.Š.) \\ 3 New Technologies Research Centre, University of West Bohemia, Univerzitni 8, \\ 30100 Pilsen, Czech Republic; zjansa@ntc.zcu.cz \\ 4 Metrology Laboratory Regional Technological Institute, University of West Bohemia, Univerzitni 8, \\ 30100 Pilsen, Czech Republic; kubatova@rti.zcu.cz \\ * Correspondence: bricda@kmm.zcu.cz; Tel.: +420-377-638-314
}

Received: 13 October 2020; Accepted: 03 November 2020; Published: 6 November 2020

\begin{abstract}
The study focuses on microstructural evolution in a WC-Co powder mixture during Selective Laser Melting (SLM) and hot isostatic pressing (HIP) processing. This powder mixture contained a $13 \pm 0.6 \%$ weight fraction of Co binder and WC particles of mean size of $3.0 \pm 1.9 \mu \mathrm{m}$. SLM of the mixture produced samples of various densities, depending on the volumetric energy density (VED) applied. High VED levels led to densities of up to $88 \%$. The aspects affected by changes in VED included the pore density as well as the resulting types of phases and the size of WC phase particles. At high VED, the material began to develop cracks due to embrittlement. This had multiple causes: coarsening of $\alpha$-phase (WC), evaporation of $\beta$-phase (Co binder), and precipitation of $\eta$-phase. At low VED levels, pores formed, typically of nonsymmetric shapes, with sizes larger than $500 \mu \mathrm{m}$. Subsequent HIP processing led to an increased density, up to $96 \%$ of solid material. Contributions to this increased density were provided by structure transformations, namely, coarsening of $\alpha$-phase by up to $1300 \%$ when compared to the powder grain size, and formation of $\eta$-phase. The results provided a basis for steering further research to explore to a greater depth the SLM and HIP processing of selected WC-Co powder mixtures with as yet unused ranges of process parameters.
\end{abstract}

Keywords: WC-Co; cemented carbides; SLM; HIP; porosity; grain coarsening; eta phase; density; CC structures

\section{Introduction}

The structure of cemented carbides (CC) substantially depends on their manufacturing route. It may involve various techniques which include production of powder mixtures, their compaction, and sintering. The typical resulting microstructure of a cemented carbide consists of hard WC carbide particles ( $\alpha$-phase), tough metallic binder of Co ( $\beta$-phase) and certain other carbides ( $\gamma$-phase) with tetragonal crystal structure. These constituents and their size and amount in the structure govern the mechanical and physical properties of CC and its intended use [1-5].

Typical applications of CCs include cutting tools and parts subjected to wear, such as nozzles, throwing blades, and molds for large-series production [6,7]. All these parts share one feature: very simple shapes of their outside and interior surfaces. To some extent, these surfaces can be adjusted for a specific application by subsequent processing, which may include grinding, tumbling 
and laser ablation [8-10]. However, these processes may not necessarily improve the product properties. An option which can deliver improvement is additive manufacturing (AM) [11,12].

Several AM techniques are available for making cemented carbide products [13,14]. One of them is the SLM process. In SLM, a machine part, for instance, is made by deposition of consecutive powder layers. After each layer is deposited, some regions in this layer on the powder bed are melted by laser. In this manner, the part is gradually built $[15,16]$.

Creating CC parts by this process is rather demanding. Its feasibility depends on the properties of the powder mixture and the process conditions. Powder mixtures for SLM are required to consist of spherical particles with a certain distribution of sizes 10-50 $\mu \mathrm{m}$ and surface properties which facilitate uniform energy distribution across the powder bed region to be melted by laser $[17,18]$. With steel and non-ferrous powders, the desired state of the particle surface is attained by various techniques, typically by atomization in inert gas or by plasma application $[19,20]$.

Cemented carbide powders are produced using a different method which involves mixing the constituents in attritor or ball mills followed by drying the mixture in inert gas or vacuum. The particles may eventually be passed to granulation [1,2].

Conventional techniques may yield a relatively wide range of WC-Co particle geometries with various bonds between the constituents. The powders may therefore differ in their flowability and ability to produce a uniform layer on the build plate in an AM machine. For the SLM process and for achieving the right energy distribution across the powder bed, it is important that each powder layer is flat and continuous.

These carbide mixtures also show another difference from conventional powders. Their multiphase structure comprises no fewer than two constituents. One of them is the $\alpha$-phase whose melting temperature is $2720^{\circ} \mathrm{C}$ and whose evaporation temperature is $6000{ }^{\circ} \mathrm{C}$. The other is $\beta$-phase with melting and evaporation temperatures of $1495^{\circ} \mathrm{C}$ and $2870{ }^{\circ} \mathrm{C}$, respectively, provided that $\beta$-phase is cobalt.

Cobalt is the most frequent choice because it has excellent wettability with WC grains of $\alpha$-phase. Thanks to this property, it covers the $\alpha$-phase grains entirely during sintering and forms a skeleton which lends toughness to CCs [1]. As opposed to conventional sintering, SLM produces connection between particles over a very short time, typically under $0.1 \mathrm{~s}$ [21]. The growth of these initial joints between powder particles causes gradual decrease of porosity in the CC structure.

The final degree of consolidation of the powder mixture primarily depends on how stable the viscous flow of the melted binder is while it fills the voids between the tungsten carbide. Scherer found, in 1977, that this degree is in fact inversely proportional to the viscous flow and can be described using the Equation (1) [15].

$$
x=\frac{3(1-\rho) \pi \gamma a^{2}}{24 \eta_{m} \rho^{3} r^{3}}\left[r-(1-\xi) x+\left(x-\left(x i+\frac{1}{3}\right) r\right)\right] \frac{9\left(x^{2}-r^{2}\right)}{18 r x-12 r^{2}}
$$

where $\rho\left[\mathrm{kg} / \mathrm{m}^{3}\right]$ is the apparent density, $\gamma[\mathrm{N} / \mathrm{m}]$ is the particle surface tension, $\xi$ is a parameter with its magnitude between 0 and 1 , and $\eta_{m}[\mathrm{~Pa} \mathrm{~s}]$ is the viscosity of the solid liquid mixture [15].

Here, the viscosity of the mixture of the liquid binder and the solid phase (WC grains) can be expressed by the Equation (2) [15].

$$
\eta_{m}=\eta_{l}\left(1-\frac{V_{s}}{V_{m}}\right)^{-2}
$$

where $\eta_{l}[\mathrm{~Pa} s]$ is the viscosity of the liquid phase, $V_{s}\left[\mathrm{~m}^{3}\right]$ is the fraction of the solid phase, and $V_{m}\left[\mathrm{~m}^{3}\right]$ is the critical volume fraction above which the mixture exhibits essentially viscosity [15].

Another factor at play when it comes to the final density of the CC structure is the mutual solubility of the phases and their mixing [15,22]. Mixing of the structural phases is driven by temperature gradients in the powder bed. They generate thermocapillary flow known as Marangoni 
convection. It reduces the temperature gradients in the powder bed and can be expressed in terms of the Equation (3) [22].

$$
M_{a}=\frac{\left(\frac{d_{y}}{d_{x}}\right)\left(\frac{W}{\eta}\right)}{\left(\frac{\kappa}{W}\right)}=\frac{\left(\frac{d_{y}}{d_{T}}\right)\left(\frac{d_{T}}{d_{x}}\right)\left(\frac{W}{\eta}\right)}{\left(\frac{\kappa}{W}\right)}
$$

where $W[\mathrm{~m}]$ is the linear size of the pool, $\frac{d_{T}}{d_{x}}[\mathrm{~K} / \mathrm{m}]$ is the temperature gradient, $\kappa\left[\mathrm{m}^{2} / \mathrm{s}\right]$ is thermal diffusivity, and $\eta[\mathrm{Pa} \mathrm{s}]$ is the viscosity [22]

The magnitude of temperature gradients in the powder bed substantially depends on AM parameters. The layer thickness, laser power and scan speed and other parameters dictate the amount of energy available for melting the material in the powder bed, and therefore the structure of the resulting CC. For instance, the volumetric energy density (VED) can be described using the Equation (4) $[21,23,24]$.

$$
E=\frac{P}{v \cdot h \cdot t}
$$

where $P[\mathrm{~W}]$ is the power of the laser, $v[\mathrm{~m} / \mathrm{s}]$ is the motion speed of the laser spot, $h[\mathrm{~m}]$ is distance among the motion vectors, and $t[\mathrm{~m}]$ is the thickness of the powder layer.

According to available studies, the final structure of SLM-produced cemented carbide comprises a certain amount of pores, coarse grains of $\alpha$-phase (WC) and $\eta$-phase which forms in the process, basically regardless of the AM conditions used for the powder mixture [21,25-32]. The formation of $\eta$-phase is related to the cooling rate from the melting temperature. In the powder bed, the material only becomes melted for a very short time. Therefore, the matter (atoms, molecules, and ions) can only travel across short distances, which leads to regions depleted of some elements, such as carbon. As a result, the distribution of elements becomes nonuniform.

This, combined with the effects of cooling rate, then leads to formation of complex $\mathrm{W}$-Co-C carbides, referred to as $\eta$-phase, in carbon-depleted regions. When it comes to altering the structure produced by SLM, one of the available options is hot isostatic pressing (HIP). It involves application of hydrostatic pressure up to $400 \mathrm{MPa}$ and high temperatures, up to $2000^{\circ} \mathrm{C}$, and it can profoundly change the structure of the workpiece-not just in terms of porosity, but also phase composition [33-35].

The focus of this study was to use the SLM technology with a chosen WC-Co mixture and produce a cemented carbide structure which is suitable for subsequent HIP processing. For this purpose, the powder mixture was converted into several samples using various SLM conditions. The goal was to create samples that exhibit various amounts and types of porosity and different proportions of phases. The samples were then reprocessed using HIP.

After each of the processes, the microstructure of each sample was studied and evaluated. Based on the findings, the most appropriate SLM parameters for subsequent HIP were identified for the powder mixture. In addition, its microstructural evolution induced by SLM and HIP was mapped.

\section{Materials and Methods}

\subsection{Experimental Material}

The experimental material was a WC-Co powder mixture under the brand name AM WC701(AW701) marketed by the company Global Tungsten \& Powders Corp., Bruntál, Czech Republic. Prior to AM, the powder was examined while considering the requirements of the process. The size distribution and shapes of the powder particles were determined. Their flowability, bulk density, and ability to spread uniformly on the build plate were determined. These properties were then compared to those found in the commercial powder of $\mathrm{PH} 1$ precipitation-hardenable steel which has been designed for this AM process. This reference powder was designed by EOS GmbH and supplied by 3R Systems s.r.o., Jaroměř, Czech Republic. Figure 1 shows comparison of analyzed powder particles. Particles of the PH1 stainless steel powder had smooth surface with small amount of defects. Their surface contained mainly defects called satellites. In the case of AW701 powder, 
more types of surface defects were observed. Apart from satellites, craters and cavities were identified in a large amount.

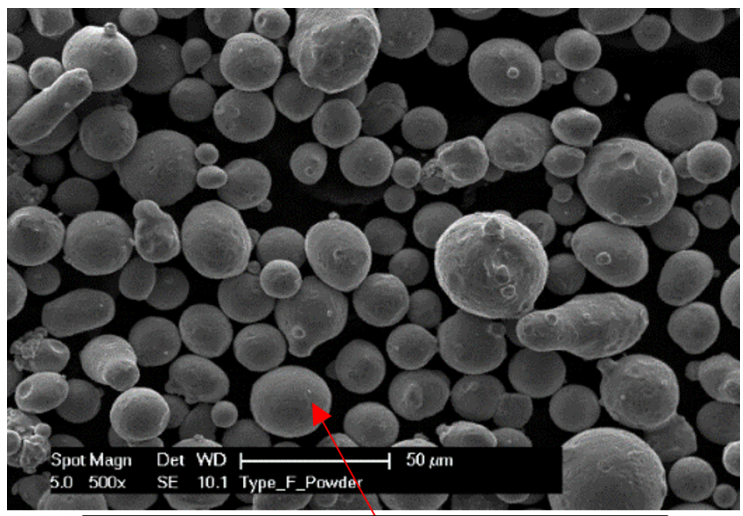

Particles of the powder PH1

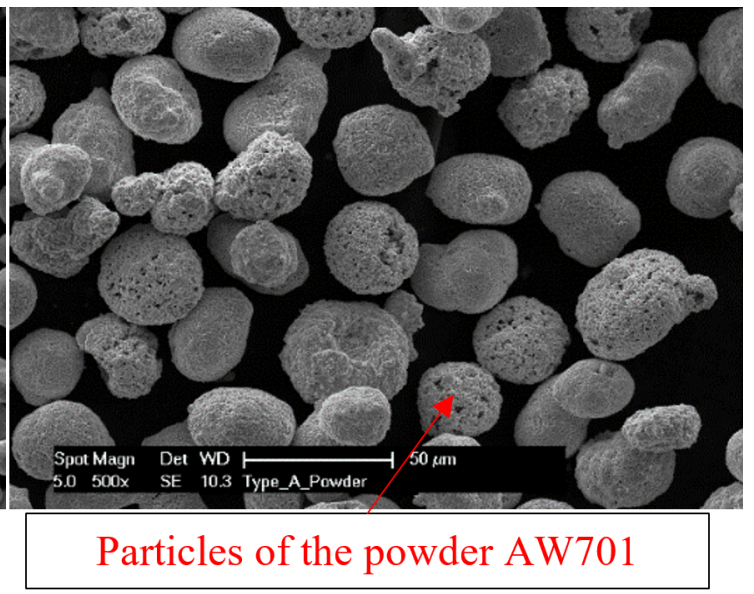

Particles of the powder AW701

Figure 1. The shape of particles of AW701 powder mixture and PH1 steel powder.

The AW701 powder particles also vary in their shape. Generally, the shape is spherical but more irregular than the PH1 powder particles, see Figure 2. In addition, a difference in the particle size profile of the two compared powders was noted, see Figure 3.

Recorded differences in the surface quality of the powder particles and the differences in their shape and size significantly affect the ability of the powder to form a uniform layer. This fact was verified by the spread test during which the layer is applied by recoater blade on the build plate of the used AM machine (Figure 4).

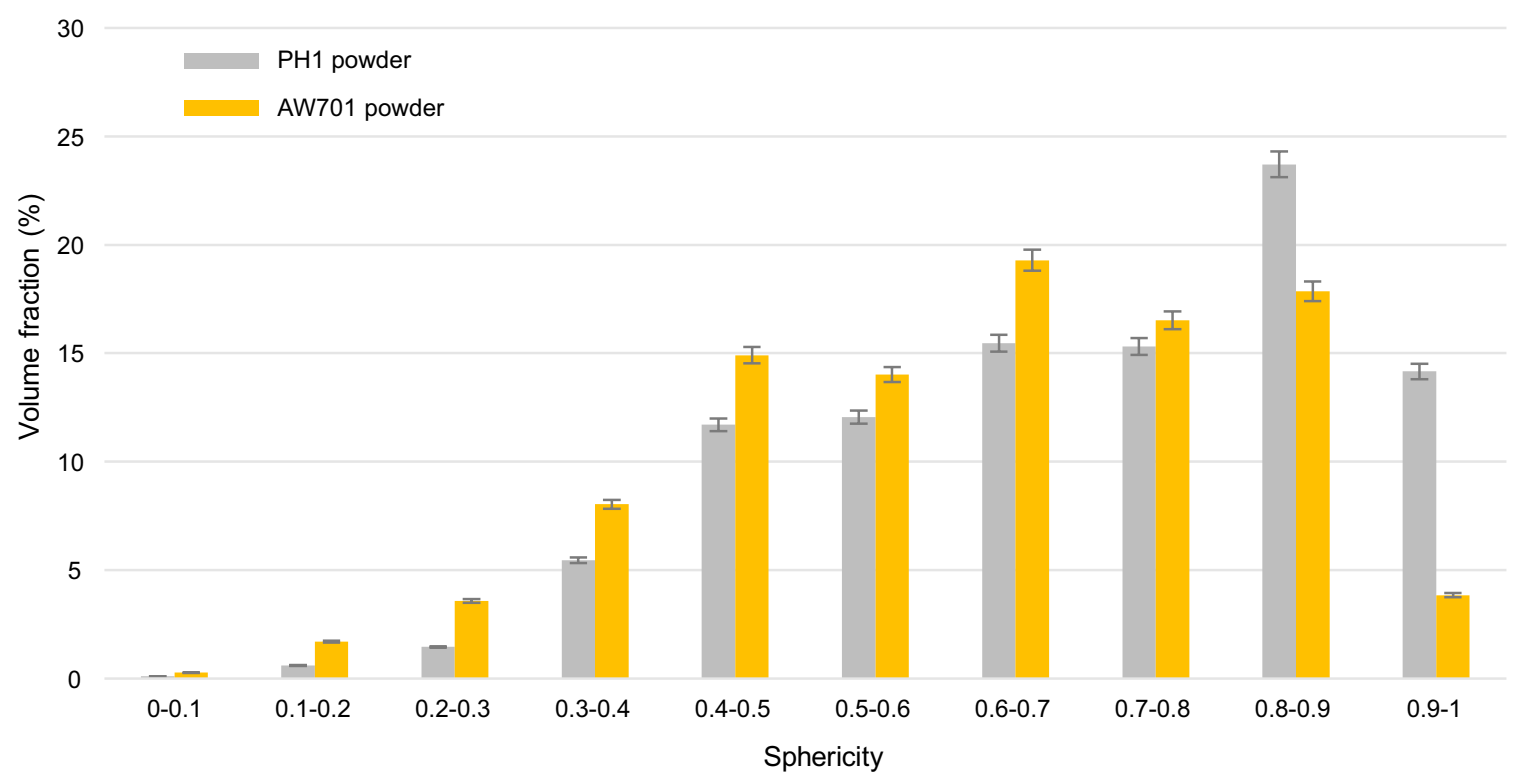

Figure 2. Sphericity analysis for the two studied powders [36]. 


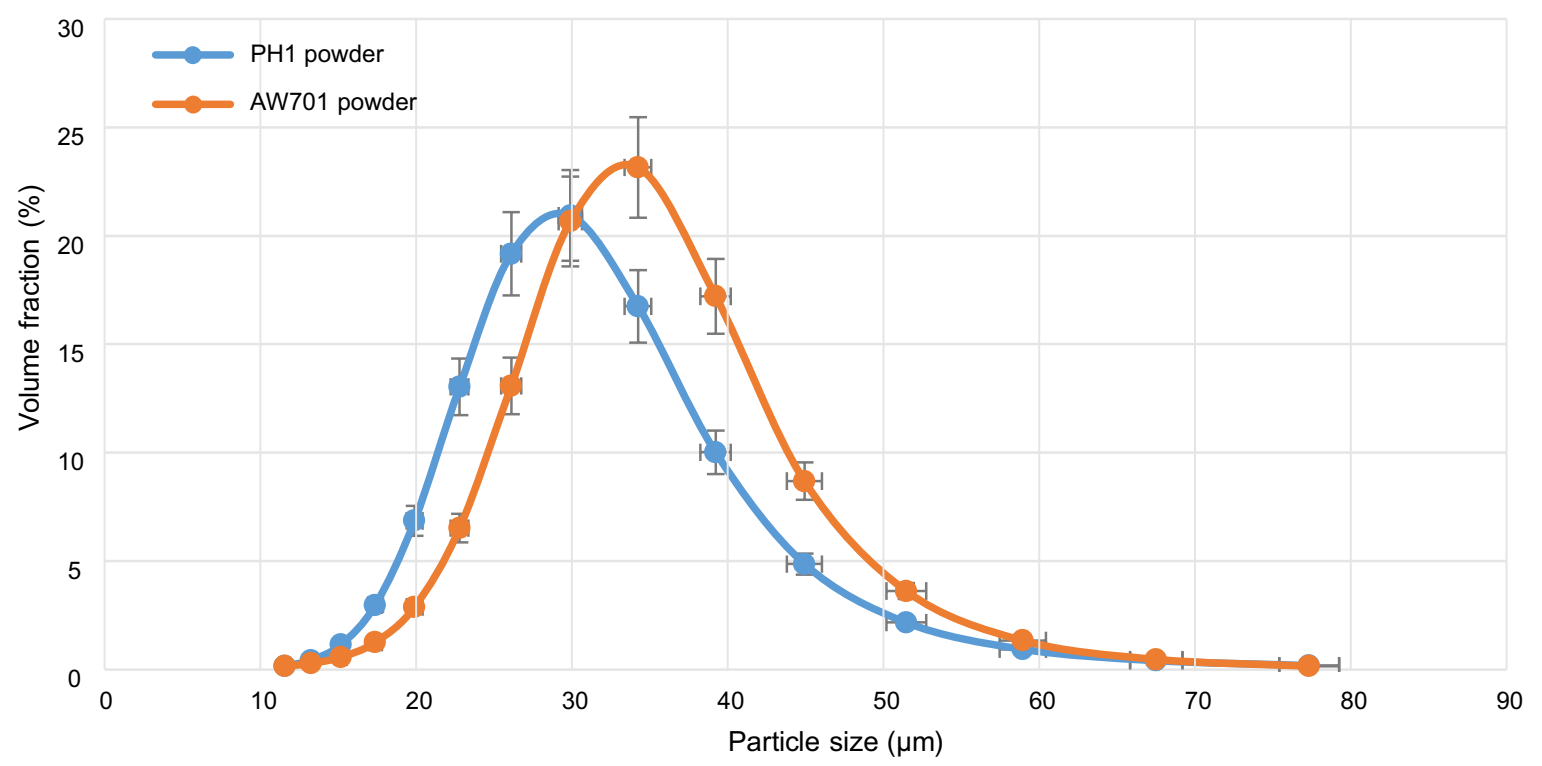

Figure 3. Size distribution for the two studied powders [36].

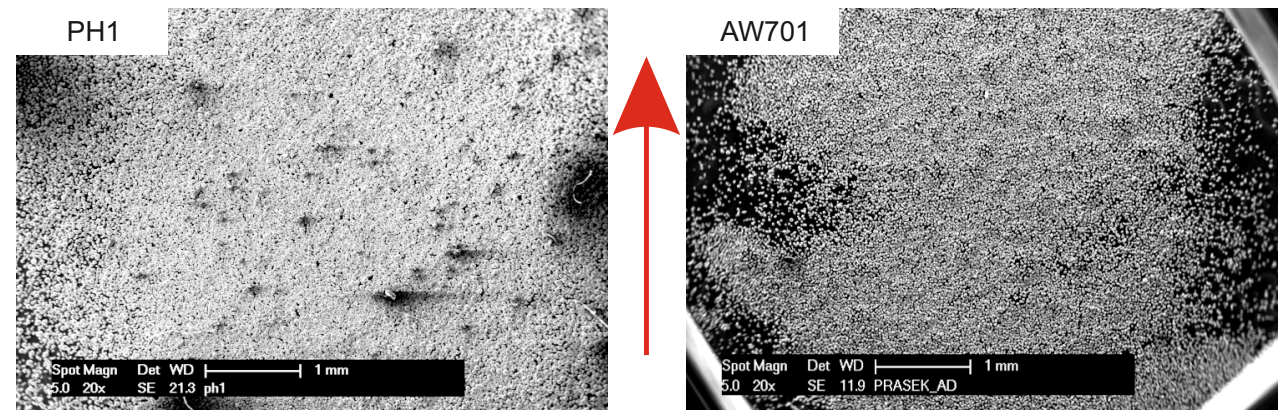

Figure 4. Micrographs of spread test on the build plate of the AM machine. The arrow indicates the direction of movement of the recoater blade.

The relatively lower fraction of fine powder particles indicated in the plot in Figure 3 had a favorable impact on the flowability and other technological properties of the powder, as evidenced in Table 1 . The reason is that the capacity for friction between particles was reduced.

Table 1. Technological properties of AW701 powder mixture and PH1 powder.

\begin{tabular}{ccc}
\hline Powder Type & AW701 & PH1 \\
\hline Flowability $[\mathrm{s} / 0.2 \mathrm{~kg}]$ & $2.7 \pm 0.2$ & $3.7 \pm 0.1$ \\
Bulk density $\left[\mathrm{kg} / \mathrm{m}^{3}\right]$ & $5970 \pm 900$ & $4200 \pm 600$ \\
Tap density $\left[\mathrm{kg} / \mathrm{m}^{3}\right]$ & $7290 \pm 110$ & $4600 \pm 700$ \\
Mean spread powder width $[\mathrm{mm}]$ & $4.6 \pm 0.5$ & $3.5 \pm 0.5$ \\
\hline
\end{tabular}

The phase composition of the virgin powder mixture was determined by means of X-ray diffraction in order to obtain reference values for evaluating structural changes upon SLM. Its chemical composition was measured by EDS. The virgin grain size of $\alpha$-phase was found by metallographic analysis. The results are listed in Figure 5. 


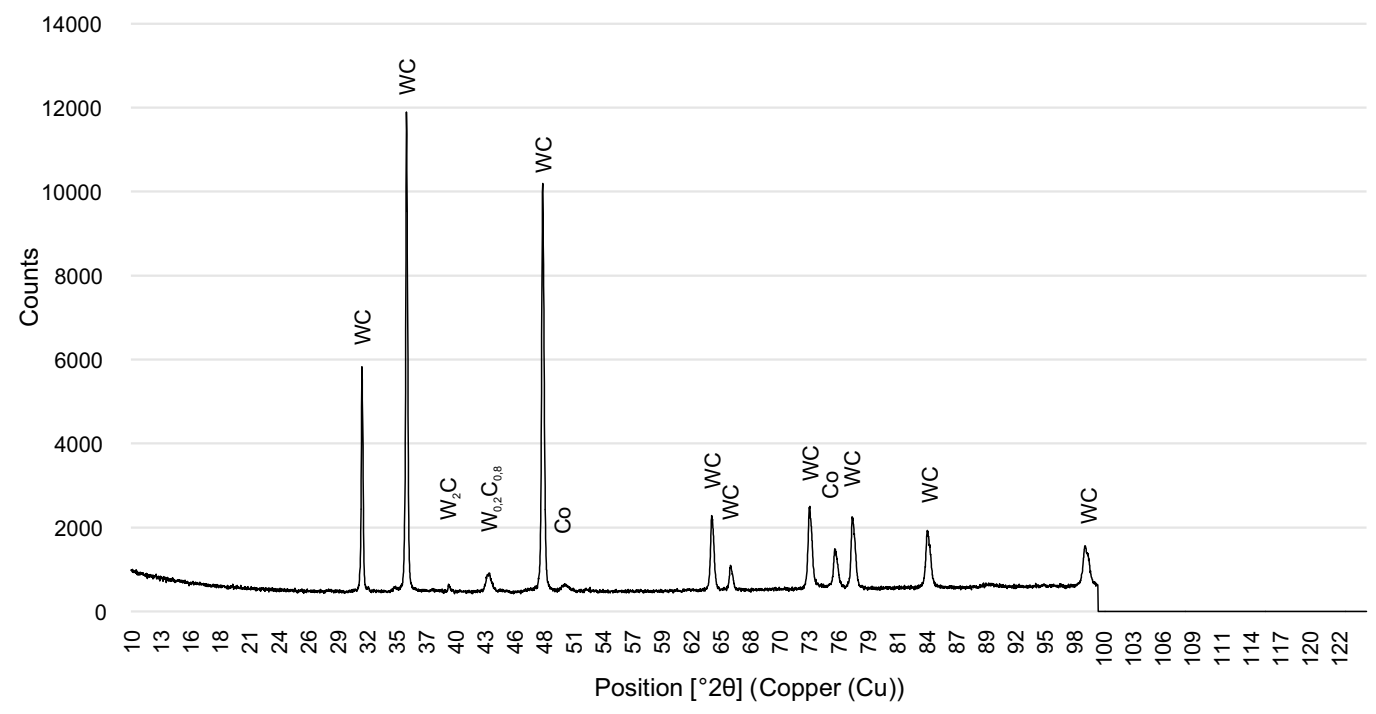

Figure 5. Phase composition of particles of AW701 powder mixture. EDS analysis found that the particles contain $13 \pm 0.6 \mathrm{wt}$.\% of Co binder. The particle size of $\alpha$-phase was $3.0 \pm 1.9 \mu \mathrm{m}[36,37]$.

Powder Mixtures

The size distribution and shapes of particles of the powders were determined using metallographic techniques. Powder samples were mounted and metallographic sections were prepared and examined using PHILIPS XL30ESEM scanning electron microscope (FEI Company, Hillsboro, OR, USA) and imaging with SE and BSE. The magnification was 100-1500 $\times$ and the micrographs were taken using AxioVision (Carl Zeiss s.r.o., Prague, Czech Republic) and NIS ELEMENTS (Laboratory Imaging s.r.o., Prague Czech Republic) software tools. Chemical composition was measured by EDS. The technological properties of the powders (flowability, bulk density) were determined with reference to EN ISO 4490 [38]. PANalytical X'Pert PRO automatic powder diffractometer (Malvern Panalytical, Eindhoven, Netherlands) with Bragg-Brentano geometry was employed to measure the phase composition of the powders. The X-ray source had copper anode $\mathrm{CuK}_{\alpha}\left(\lambda_{k_{\alpha}}=0.15405980 \mathrm{~nm}\right)$.

\subsection{Selective Laser Melting Technology}

Selective Laser Melting is one of powder bed manufacturing techniques. Thin powder layers are deposited across the entire build area and selectively melted in locations defined in the input CAD data. After each cycle, the build platform descends by a thickness of a single layer and another cycle is performed (Figure 6). Today, it can be used with various metallic materials based on iron, nickel, aluminum, and titanium.

One of the main fields of application of this technology involves process trials on new materials. In most cases, the goal is to find parameters which lead to the least porosity and superior appearance of the outer surfaces [39-41]. Typically, four parameters are reported in professional publications as those which dictate the quality of the product. They are the laser beam power $P[\mathrm{~W}]$, scan speed $v[\mathrm{~mm} / \mathrm{s}]$, layer thickness $t[\mathrm{~mm}]$, and the spacing between laser paths $h[\mathrm{~mm}]$. These parameters are incorporated in the volumetric energy density constant $E\left[\mathrm{~J} / \mathrm{mm}^{3}\right]$ (Equation (4)) [24]. Once the appropriate set of process parameters are found, the volumetric energy can be used for altering the process, for instance, to improve productivity by changing the scan speed. 


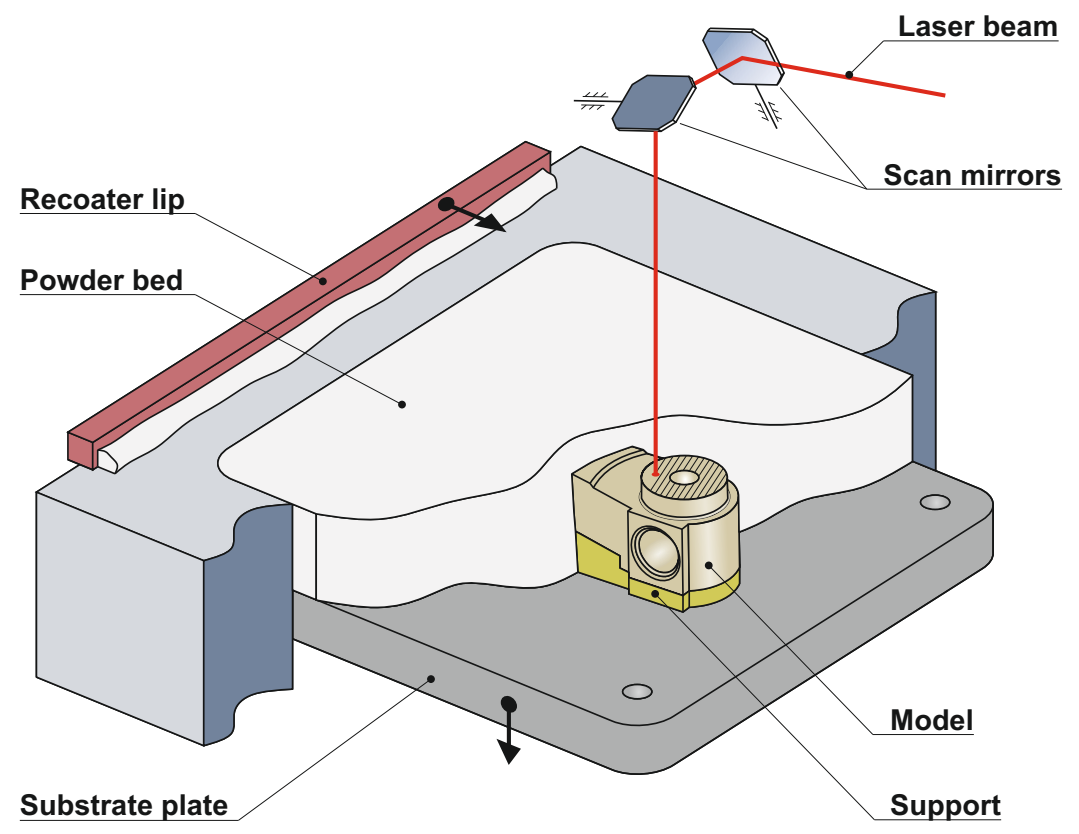

Figure 6. Schematic representation of the Selective Laser Melting process.

\subsection{The Methodology of Testing Powder Mixture AW701}

The additive manufacturing sequence was carried out in SLM 280HL equipment (SLM Solutions Group AG, Lübeck, Germany) which features a single Yb:YAG (IPG Photonics) fiber laser of $400 \mathrm{~W}$ nominal power. Its maximum build space size is $280 \times 280 \times 350 \mathrm{~mm}$. For these experiments, the reduced space size was $100 \times 100 \times 120 \mathrm{~mm}$.

After considering the particle size distribution of the AW701 mixture, a layer thickness of $t=40 \mathrm{um}$ was chosen for the AM process. The laser path spacing was fixed at $h=0.12 \mathrm{~mm}$. It mainly reflects the size of the laser sport which produces the molten pool. Variable parameters for the AW701 powder mixture were then the laser power $P$ and scan speed $v$. Table 2 provides a summary of parameters for all the builds.

The scanning strategy involved hatching with $90^{\circ}$ rotation between powder layers. In the building strategy, a single contour scan was followed by interior hatching. The protective atmosphere was nitrogen gas of $97-98 \%$ purity from an internal nitrogen generator. Build plates were made of S235 steel and their size was $100 \times 100 \mathrm{~mm}$. The builds were $10 \mathrm{~mm}$ cubes placed directly on the build plate with no additional support structure.

One of the crucial deficiencies was inadequate adhesion of the first layers to the build plate (Figure 7). As a result, several builds had to be scrapped in the process because they rose above the current level and threatened to cause collision with the recoating device. It was remarkable that at $80 \mathrm{~W}$ laser power, the builds created with the lowest volumetric energy density had to be scrapped.

The subsequent HIP process on selected builds was carried out with standard parameters of sintering process at $1390{ }^{\circ} \mathrm{C}$ in an argon atmosphere at 40 bar and with a holding time at the sintering temperature $60 \mathrm{~min}$ in cooperation with Dormer Pramet s.r.o, Šumperk, Czech Republic. The builds selected for the HIP process were those with low $\left(E=60 \mathrm{~J} / \mathrm{mm}^{3}\right)$ and high $\left(E=520 \mathrm{~J} / \mathrm{mm}^{3}\right)$ energy densities. 
Table 2. Process parameters for AW701 powder mixture.

\begin{tabular}{|c|c|c|c|}
\hline $\begin{array}{c}\text { Laser Power } \\
P[\mathrm{~W}]\end{array}$ & $\begin{array}{c}\text { Scan Speed } \\
v[\mathrm{~mm} / \mathrm{s}]\end{array}$ & $\begin{array}{l}\text { Volumetric Energy Density } \\
\qquad E\left[\mathrm{~J} / \mathrm{mm}^{3}\right]\end{array}$ & Note \\
\hline 40 & 152 & 54 & \\
\hline 40 & 140 & 60 & \\
\hline 40 & 128 & 65 & \\
\hline 40 & 111 & 75 & \\
\hline 40 & 100 & 83 & \\
\hline 40 & 83 & 100 & \\
\hline 40 & 55.5 & 150 & \\
\hline 40 & 35 & 238 & \\
\hline 80 & 175 & 95 & Stopped \\
\hline 80 & 166 & 100 & Stopped \\
\hline 80 & 145 & 114 & Stopped \\
\hline 80 & 128 & 130 & Stopped \\
\hline 80 & 111 & 150 & Stopped \\
\hline 80 & 100 & 166 & \\
\hline 80 & 95 & 175 & \\
\hline 80 & 90 & 185 & \\
\hline 80 & 85 & 196 & \\
\hline 80 & 80 & 208 & \\
\hline 80 & 75 & 222 & \\
\hline 80 & 70 & 238 & \\
\hline 80 & 49 & 340 & \\
\hline 80 & 32 & 520 & \\
\hline 100 & 209 & 99 & \\
\hline 100 & 181 & 115 & \\
\hline 100 & 139 & 149 & Stopped \\
\hline 100 & 87.5 & 238 & \\
\hline 100 & 61.2 & 340 & \\
\hline 100 & 40 & 520 & \\
\hline
\end{tabular}

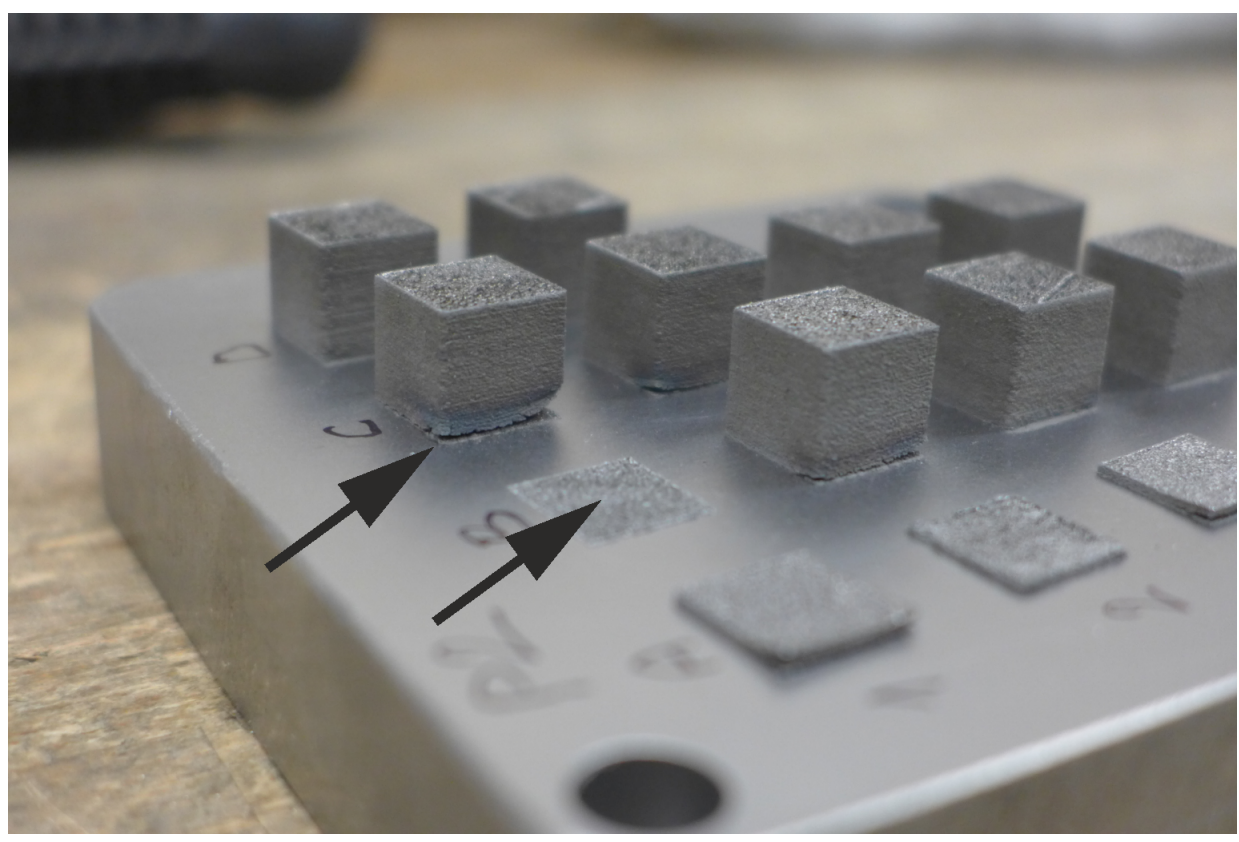

Figure 7. Poor adhesion of the initial layers of AW701. 
Samples after SLM Process and HIP Process

Metallographic specimens were examined using PHILIPS XL30ESEM (FEI Company, Hillsboro, OR, USA) and Tescan MIRA3 (TESCAN ORSAY HOLDING, a.s., Brno, Czech Republic) scanning electron microscopes and a CarlZeiss Observer Z1m optical microscope (Carl Zeiss s.r.o., Prague, Czech Republic). The metallographic sections were oriented in the transverse direction to the building direction. The features of interest were the pore structure, microstructural phases and changes in the chemical composition (determined by EDS). The microstructures were revealed by chemical etching with reference to ASTM B657 [42].

AxioVision (Carl Zeiss s.r.o., Prague, Czech Republic) and NIS ELEMENTS (Laboratory Imaging s.r.o., Prague Czech Republic) software tools aided in the evaluation of micrographs. Changes in the specimen shape caused by the SLM and HIP processes were measured using the Zeiss Prismo 7 Navigator machine (Carl Zeiss s.r.o., Prague, Czech Republic) with Zeiss VAST XXT measuring head. The size of the ruby probe tip was $1.5 \mathrm{~mm}$ and its length was $50 \mathrm{~mm}$. The probe approached from the top along $\mathrm{Z}$ axis. Using $\mathrm{X}$-ray diffraction, changes in the phase composition and structure were mapped.

The automatic powder diffractometer PANalytical X'Pert PRO (Malvern Panalytical, Eindhoven, Netherlands) had a copper source $\left(\lambda_{k_{\alpha}}=0.154187 \mathrm{~nm}\right)$ with ultra-high speed solid state PIXcel detector. The data was stored in a computer memory. For the sake of comparison, the measurement settings were identical for all the specimens. The aperture for the vertical direction was set at $20 \mathrm{~mm}$, the same value as for the software-controlled horizontal aperture. The measurement range was 30 to $100^{\circ} 2 \theta$ using the symmetric Bragg-Brentano geometry.

\section{Results}

\section{Samples after SLM Process and HIP Process}

In the builds produced by SLM, low energy levels already led to creation and gradual expansion of connections between particles, as seen in Figure 8. With increased energy densities, the volume of these joints and their density grew.

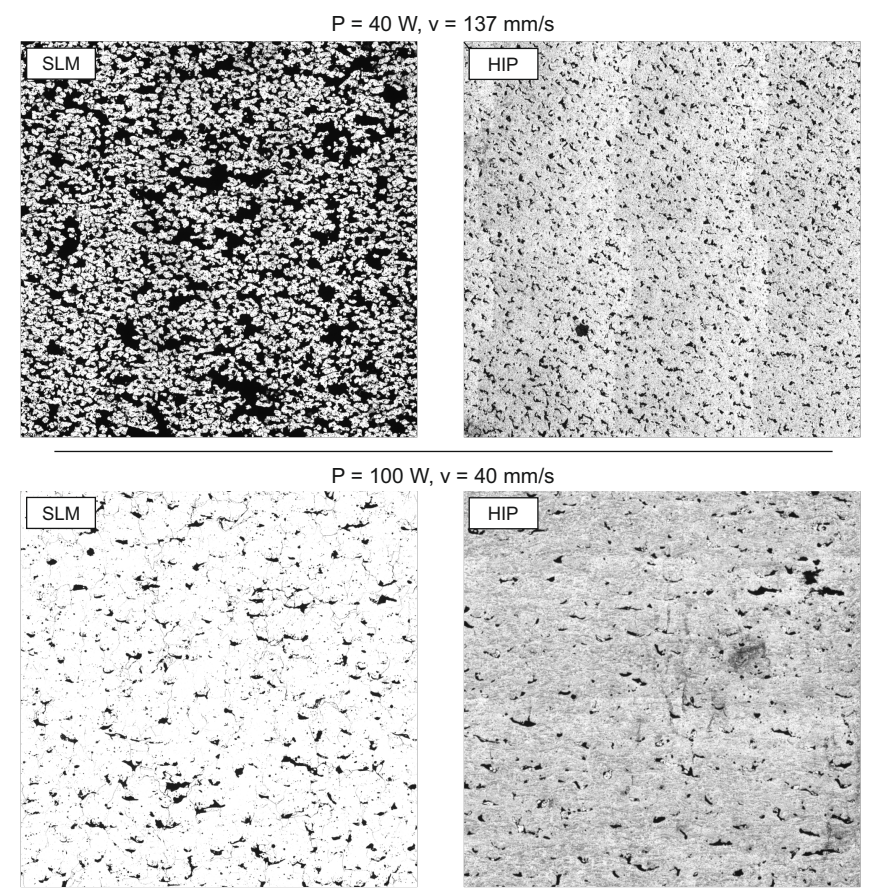

Figure 8. Macrographs showing the distribution of sizes and shapes of pores for low and high energy densities before and after the hot isostatic pressing (HIP) process. 
The best density achieved in these experiments was $88 \%$. As density increased, the size and shape of pores changed, see Figures 9 and 10.
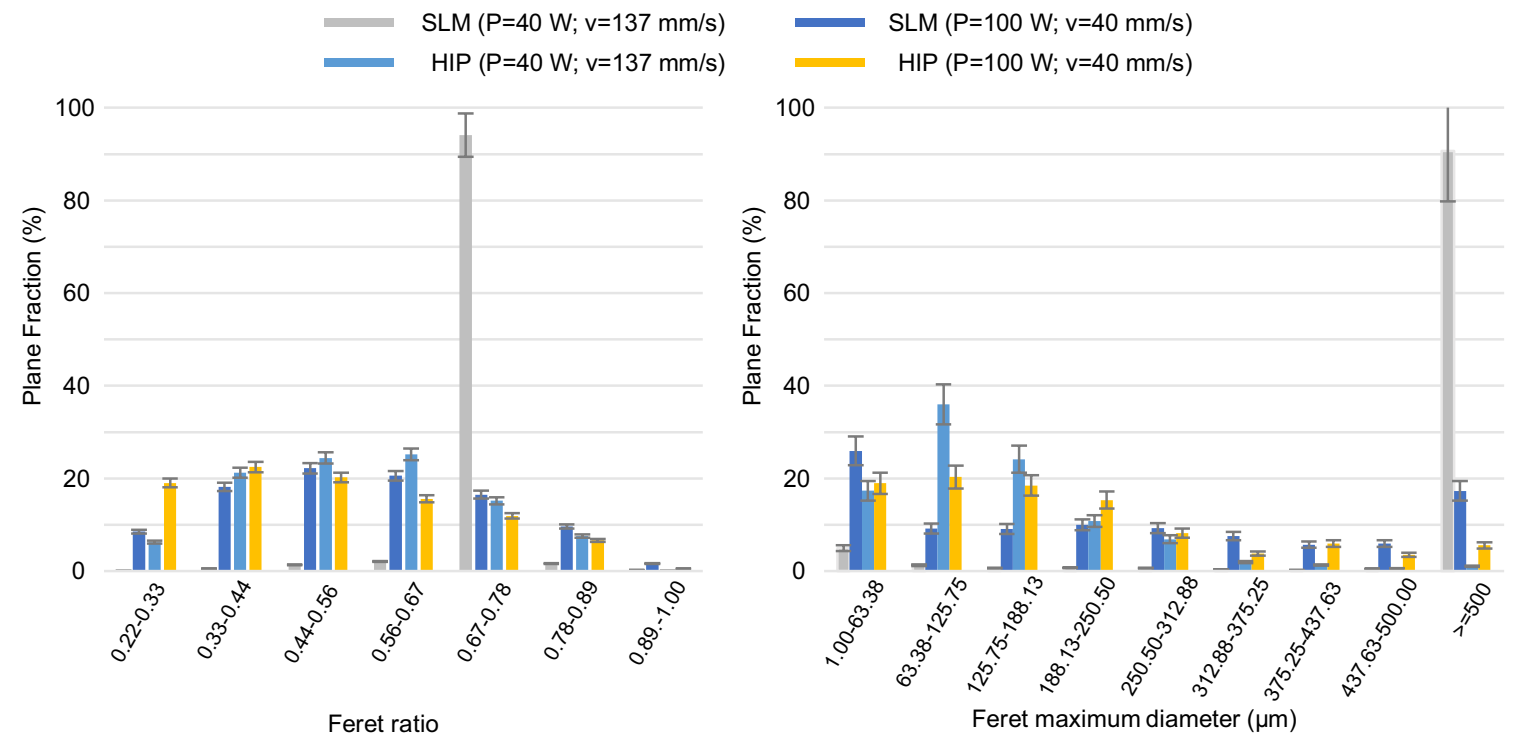

Figure 9. Distribution of sizes and shapes of pores for low and high energy densities before and after the HIP process.

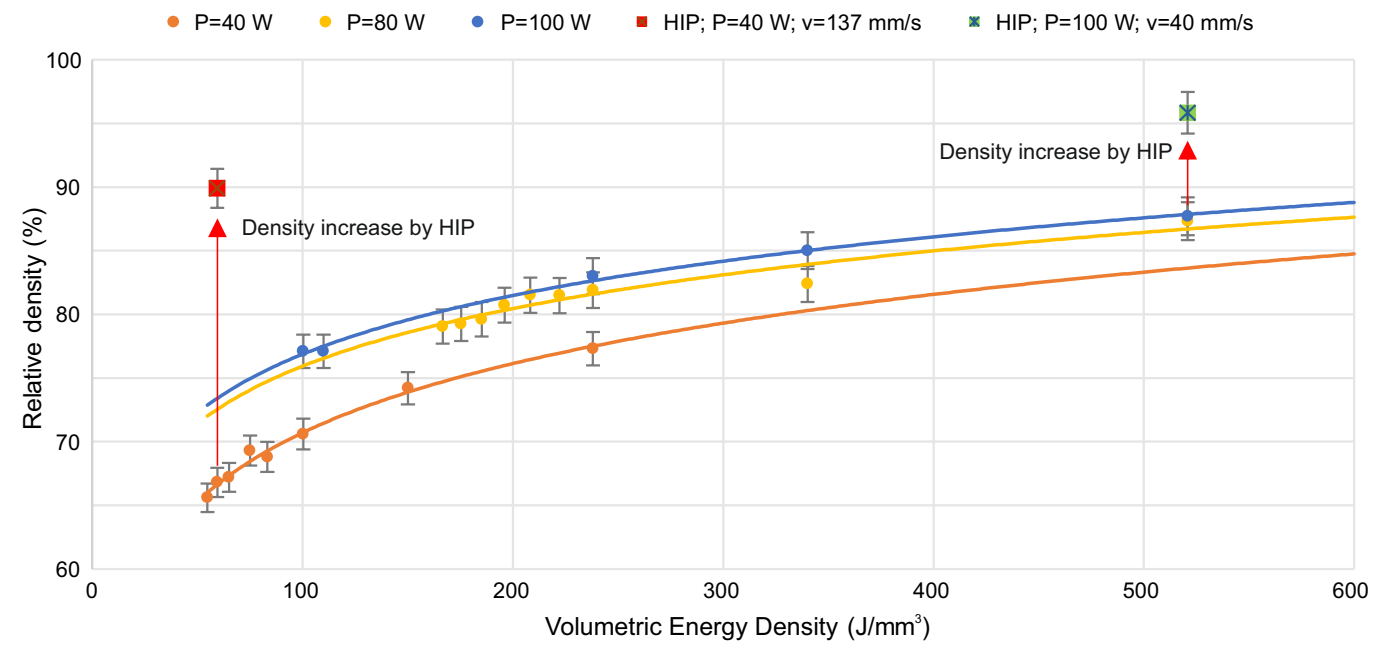

Figure 10. Relationship between energy density and subsequent HIP process and final density of builds from AW701 mixture.

The initial interconnected pores sized $500 \mu \mathrm{m}$ and larger which formed at energy densities of less than approximately $100 \mathrm{~J} / \mathrm{mm}^{3}$ became closed pores as the energy density was increased. When VED exceeded approximately $200 \mathrm{~J} / \mathrm{mm}^{3}$, cracks developed. Cracking is associated with temperature gradients which exist in SLM builds [27,29,43].

The pores fall into several groups. In the first group, the pores form due to nonuniformities in the powder bed or low VED values resulting from low power P [W] setting or high speed of laser movement. As a result, the material in the powder bed was only melted for very short periods of time and in narrow locations, and the molten pool was unstable [44]. The result was pores with non-uniform shapes and sizes which sometimes exceeded the layer thickness. The second group comprises round pores. Most of them are smaller than the powder layer thickness. Their origin is related to the reaction between the melted powder bed and the gas phase. It may be an interaction between the inert atmosphere and the powder bed or a reaction caused by residual moisture in the powder bed. As a result, partial pressure of gas occurs at the interface with the melt. 
The amount of pressure substantially depends on the gas type. The subsequent HIP process eventually eliminates the cracks as well as the closed pores which formed due to interaction between the melt and the gas phase. As a result, the relative density of the specimens made at high VED increased to $96 \%$ (Figure 10). The final density in specimens with low VED levels was $90 \%$.

In specimens created at low VED, the density was considerably improved by gradual elimination of the connected pores. The chosen scanning strategy contributed to this elimination as it helped create a skeleton which isolated the individual pores. Another contributing factor was the presence of unsintered particles which helped gradually shut the pores during HIP.

Cemented carbides are composite materials that contain phases whose solidus, liquidus, and evaporation temperatures differ, which means that they evaporate during processing. The amount of evaporated material depends on VED, as illustrated in Figure 11.

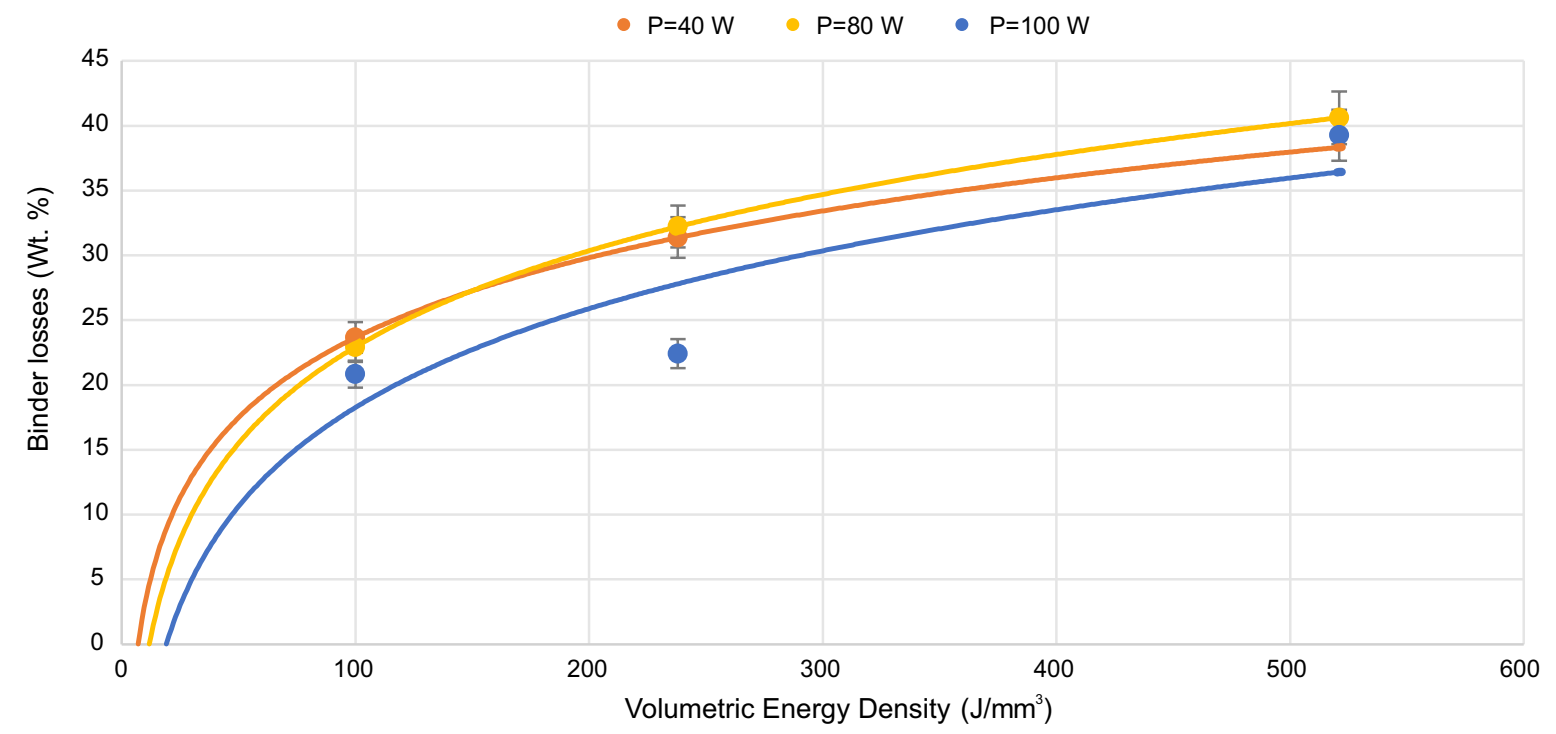

Figure 11. Co binder volume vs. volumetric energy density (VED) applied in Selective Laser Melting (SLM).

As partial pressure of gas increases with the volume of evaporated material, round pores form at higher energies and take up a larger volume. As more binder evaporates, the cemented carbide becomes more brittle which, along with temperature gradients, contributes to cracking at higher VED.

The mechanisms which contributed to densification of AW701 specimens included coarsening and changes in the morphology of $\alpha$-phase particles, as well as phase transformations caused by the diffusion of interstitial and substitutional elements across the melted portion of the powder bed in SLM and during HIP.

Figure 12 documents the changes in $\alpha$-phase in specimens processed at high VED. The micrographs show the directional growth of particles of this phase. The growth depends on the SLM parameters. Reports $[23,26]$ characterize the process as multi-laminated growth mechanism. In addition, certain grains of $\alpha$-phase with favourable orientations coalesce in the process. Changes in the morphology of this phase are aided by variation in the carbon potential which occurs at the WC-Co interface during interaction with the laser beam.

The growth of WC grains takes place in the direction of heat dissipation. In the subsequent HIP process, these grains continue to grow through Ostwald ripening [45,46]. As a result, HIP-processed specimens contained grains with sizes up to $40 \mu \mathrm{m}$. This is more than $1300 \%$ increase over the initial size.

Metallographic analysis revealed coarsening of WC grains and the presence of $\eta$-phase, both in SLM specimens and those processed with SLM and HIP. The volume fraction of this phase, as well as the final size and shape of WC grains, was controlled by the process parameters. 

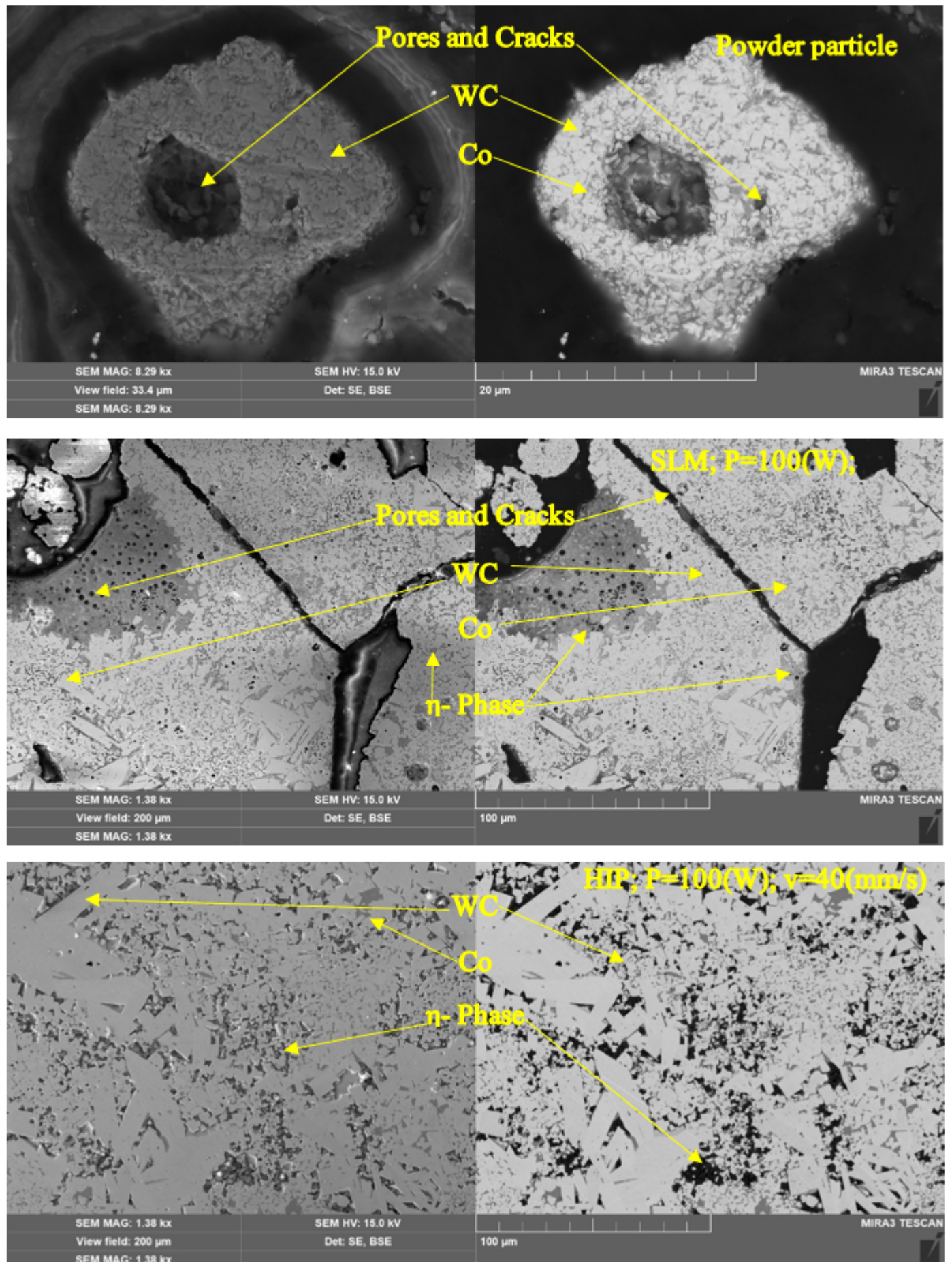

Figure 12. Microstructures produced by SLM and HIP processing. The top micrograph shows the microstructure of a virgin powder particle. The middle one shows the microstructure after SLM. The post-HIP microstructure is shown in the bottom micrograph.

Figure 13 shows the different sizes of $\alpha$-phase domains, in which coherent diffraction occurs. This is due to variation in SLM process parameters for AW701 powder mixture. The figure also presents changes in micro-stress in the crystal lattice. 

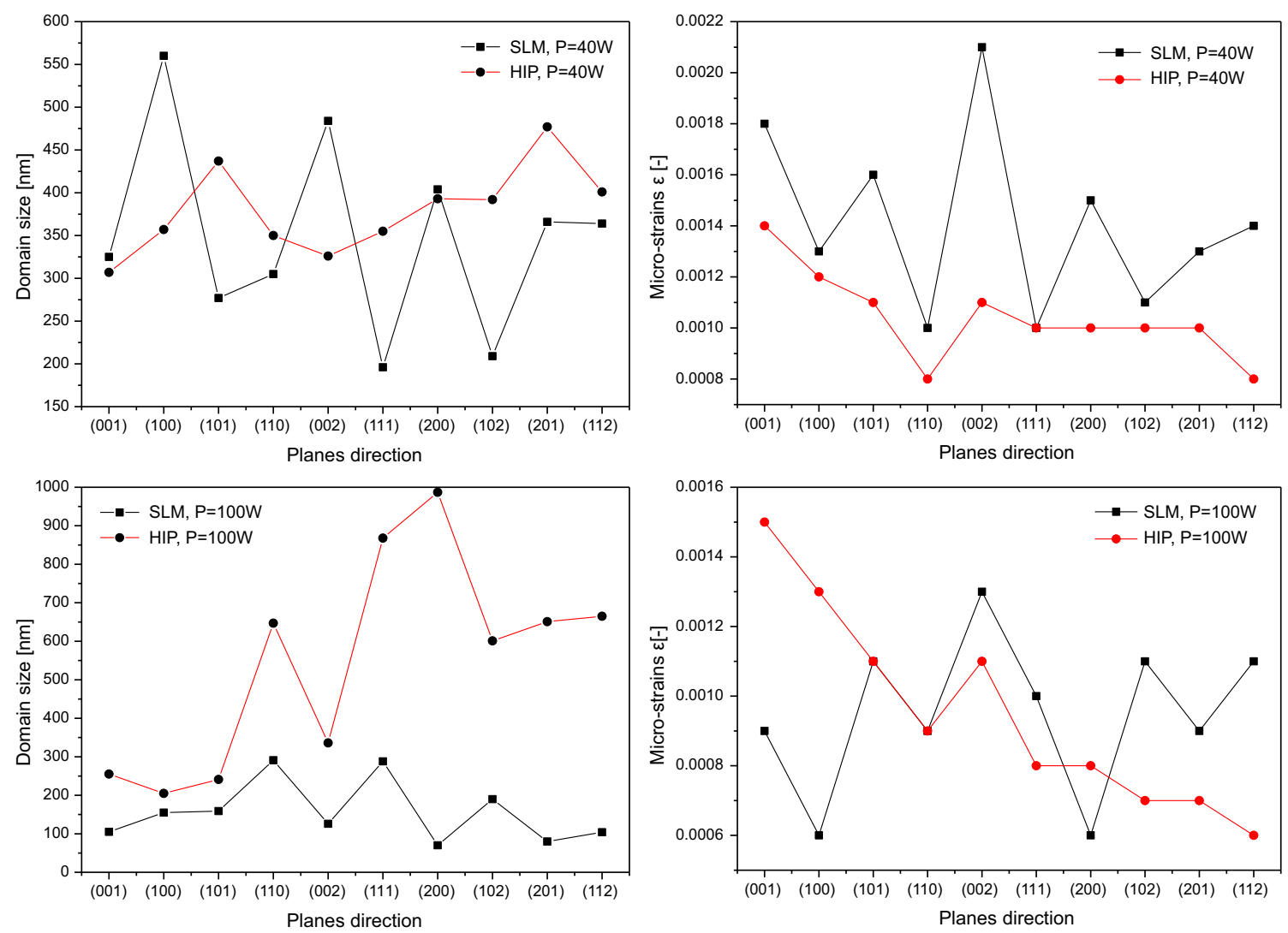

Figure 13. Comparison between $\alpha$-phase crystallite size and micro-strains after SLM in specimens prepared at low VED $(\mathrm{P}=40 \mathrm{~W})$ and high VED $(\mathrm{P}=100 \mathrm{~W})$ and their changes induced by the subsequent HIP.

The graph in Figure 13 shows that the final crystallite size depends on VED. At higher values, the $\alpha$-phase tends to coarsen more severely in the course of the subsequent HIP process. In specimens prepared at high VED, the mean post-HIP crystallite size was $620 \pm 260 \mathrm{~nm}$. In those prepared at low VED, the size was $370 \pm 50 \mathrm{~nm}$. The graph also shows that HIP had a beneficial effect on the distribution and magnitude of micro-stress in the crystal lattice that existed after SLM. The micro-stress were reduced and became more uniform.

$X$-ray diffraction of phase composition confirmed that $\eta$-phase had formed due to SLM processing. Several types of $\eta$ phase were identified in the specimens, depending on their process parameters. Details are given in Figure 14 and Table 3.

Table 3. Calculated volume fractions of phases in specimens made at low and high VED prior to and after HIP.

\begin{tabular}{|c|c|c|c|c|}
\hline Phase & $\begin{array}{c}\text { SLM } \\
P=100 \mathrm{~W} \mathrm{v}=40 \mathrm{~mm} / \mathrm{s}\end{array}$ & $\begin{array}{c}\text { HIP } \\
P=100 W v=40 \mathrm{~mm} / \mathrm{s}\end{array}$ & $\begin{array}{c}\text { SLM } \\
P=40 \mathrm{~W} \mathrm{v}=137 \mathrm{~mm} / \mathrm{s}\end{array}$ & $\begin{array}{c}\text { HIP } \\
P=40 \mathrm{~W} \mathrm{v}=137 \mathrm{~mm} / \mathrm{s}\end{array}$ \\
\hline WC & 87.5 & 92.4 & 25.3 & 97 \\
\hline $\mathrm{W}_{2} \mathrm{C}$ & 8.5 & - & 70 & - \\
\hline $\mathrm{Co}$ & 0.8 & 0.3 & 4.3 & 2.4 \\
\hline $\mathrm{Co}_{3} \mathrm{~W}_{3} \mathrm{C}$ & 0.3 & 7.3 & - & - \\
\hline $\mathrm{CO}_{6} \mathrm{~W}_{6} \mathrm{C}$ & - & - & 0.4 & 0.6 \\
\hline $\mathrm{CO}_{3} \mathrm{~W}_{9} \mathrm{C}_{4}$ & 2.9 & - & - & - \\
\hline
\end{tabular}




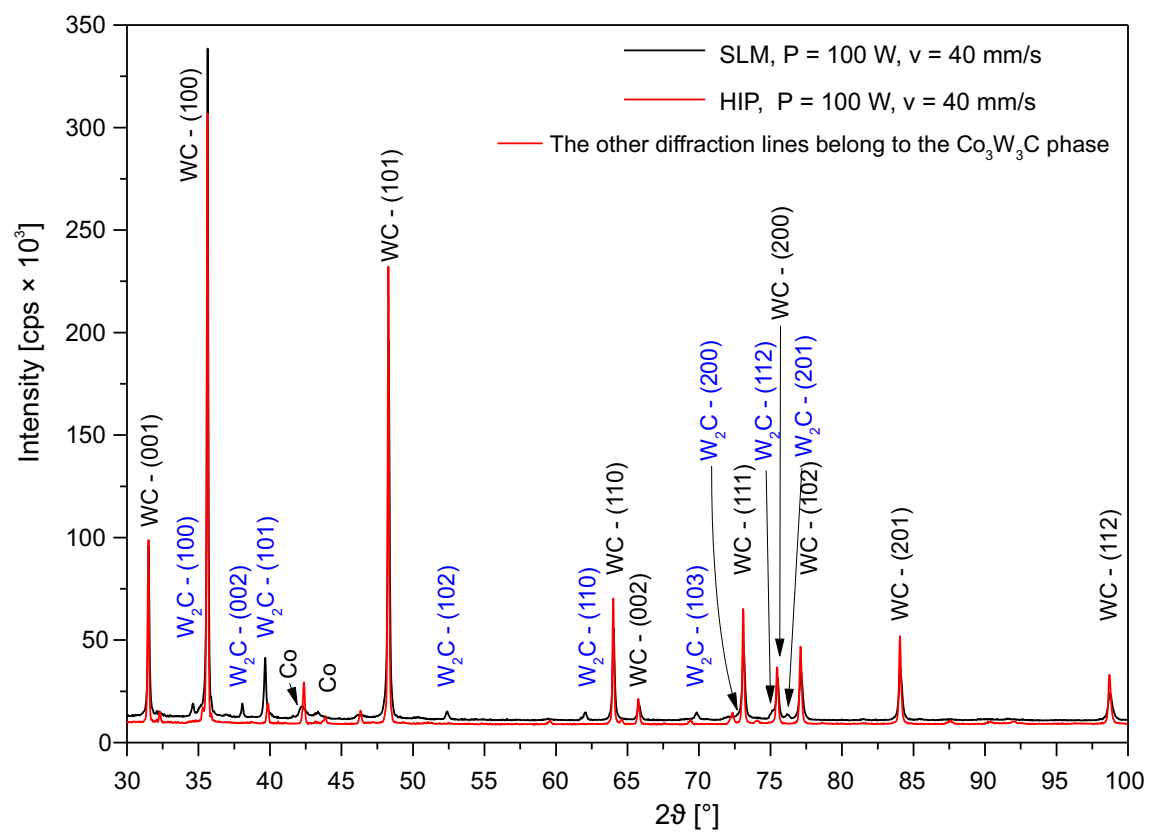

Figure 14. X-ray spectrum indicating the phase composition of specimens manufactured using high levels of VED.

In SLM specimens, the level of $\mathrm{W}_{2} \mathrm{C}$ phase, which has relatively poor stability, was higher than in virgin powder. This phase decomposed upon HIP, as did the high-temperature $\eta$-phase which had formed in specimens built at high VED levels. It was mainly due to carbon diffusion which relieved its lattice stress and enabled its transformation into more closely-packed hexagonal WC phase whose volume was larger after HIP. Free carbon then contributed to formation of the low-temperature $\eta$-phase whose volume increased after HIP as well.

\section{Conclusions}

In the present experimental study, the effect of volumetric energy density (VED) in SLM processing of WC-Co powder mixture on the resulting microstructure was explored. Prior to AM, the powder mixture was examined and its properties compared with those of a powder steel tailored to SLM. The findings from all the experiments can be summarized as follows.

- The size distribution and shape of WC-Co particles are equal to those of the reference steel powder. However, the fraction of microscopic particles which cause higher friction is lower. Consequently, the WC-Co powder mixture shows better flowability and wider spread on the build plate than the reference powder.

- By varying the amount of VED, one can control the phase structure and type of pores in SLM builds from WC-Co. By this means, interconnected irregular-shaped pores produced with VED under $100 \mathrm{~J} / \mathrm{mm}^{3}$ can be changed into closed pores and cracks at higher VED above approx. $200 \mathrm{~J} / \mathrm{mm}^{3}$. The formation of cracks was associated with the loss of Co binder-the $\beta$-phase was due to evaporation, the coarsening of $\alpha$-phase WC, the precipitation of $\eta$-phase, and stresses induced by temperature gradients. The process led to precipitation of $\eta$-phase and $\mathrm{W}_{2} \mathrm{C}$. The type of $\eta$-phase depended on the VED value. All the microstructural changes played a role in obtaining the post-SLM relative density which was $65-88 \%$, depending on VED.

The subsequent HIP process eliminated pores in all specimens, regardless of the VED value. The final relative density was $90 \%$ in specimens made at low VED and $96 \%$ in those produced with high VED levels. The mechanisms which contributed to densification in HIP included the increase in the volume of $\eta$-phase which was more pronounced in specimens produced at high VED, and coarsening 
of $\alpha$-phase, sometimes by $1300 \%$ over its initial size. The primary cause of its coarsening was the repeated decomposition of $\mathrm{W}_{2} \mathrm{C}$ phase during sintering. HIP led to less and more uniform micro-stress in the crystal lattice thanks to diffusion.

One can conclude from the above findings that appropriate settings of the additive manufacturing process can lead to specimens with interconnected pores which can be eliminated by subsequent HIP processing. One can therefore employ higher scanning speeds and lower laser power in the building process. This technology is capable of producing structures with less brittle phase ( $\eta$-phase), finer $\alpha$-phase, and lower amounts of evaporated material, namely $\beta$-phase, which causes further embrittlement.

Author Contributions: Conceptualization, D.B. and M.A.; fabrication of samples, M.A. and J.Š.; investigation, D.B., Z.J., D.K., and Z.Š.; validation, D.B. and A.K.; resources, D.B. and M.A.; writing-original draft preparation, D.B.; writing-review and editing, D.B., M.A., Z.J., D.K., and A.K.; funding acquisition, A.K. All authors have read and agreed to the published version of the manuscript.

Funding: This article was made possible by the funding for the SGS-2018-051 project "Application of new treatment and test procedures to surfaces and bulk materials for improved usability of assemblies and work tools in industry" and supported by the Ministry of Education, Youth and Sport Czech Republic_project LQ1603 Research for SUSEN.The article was also supported by the Technology Agency of the Czech Republic as part of the ZETA programme, no. TJ01000218, entitled "Manufacture of carbide cutting tool prototype by SLM additive manufacturing technique" This work has been realized within the SUSEN Project (established in the framework of the European Regional Development Fund (ERDF) in project CZ.1.05/2.1.00/03.0108 and of the European Structural and Investment Funds (ESIF) in the project CZ.02.1.01/0.0/0.0/15_008/0000293).

Conflicts of Interest: The authors declare no conflict of interest. The funder had no role in the design of the study; in the collection, analyses, or interpretation of data; in the writing of the manuscript; or in the decision to publish the results.

\section{Abbreviations}

The following abbreviations are used in this manuscript.

SLM Selective Laser Melting

HIP Hot Isostatic Pressing

VED Volumetric Energy Density

CC Cemented Carbides

AM Additive Manufacturing

EDS Energy Dispersive X-Ray Spectroscopy

\section{References}

1. Sarin, V. Comprehensive Hard Materials; Elsevier: Newnes, Australia, 2014; Volume 1, Chapters 3-4.

2. Upadhyaya, G.S. Cemented Tungsten Carbides: Production, Properties and Testing; William Andrew: Noyes, OH, USA, 1998; Chapters 3-7.

3. Kurlov, A.S.; Gusev, A.I. Tungsten Carbides; Springer International Publishing: Berlin/Heidelberg, Germany, 2013; pp. 191-237. [CrossRef]

4. Křǐž, A.; Bricín, D. Properties and Testing of Cemented Carbides; Intech: Rijeka, Croatia, 2017; pp. 273-297. [CrossRef]

5. García, J.; Ciprés, V.C.; Blomqvist, A.; Kaplan, B. Cemented Carbide Microstructures: A Review; Elsevier: Amsterdam, The Netherlands, 2019; Volume 80, pp. 40-68. [CrossRef]

6. Klaasen, H.; Kübarsepp, J. Wear of Advanced Cemented Carbides for Metalforming Tool Materials; Elsevier: Amsterdam, The Netherlands, 2004; Volume 256, pp. 846-853. [CrossRef]

7. Prakash, L.J. Application of Fine Grained Tungsten Carbide Based Cemented Carbides; Elsevier: Amsterdam, The Netherlands, 1995; Volume 13, pp. 257-264. [CrossRef]

8. Yang, J.; Odén, M.; Johansson-Jõesaar, M.; Llanes, L. Grinding Effects on Surface Integrity and Mechanical Strength of WC-Co Cemented Carbides; Elsevier: Amsterdam, The Netherlands, 2014; Volume 13, pp. 257-263. [CrossRef] 
9. Bricín, D.; Průcha, V.; Kříž, A. Texturing of WC-Co Substrate Surface to Improve the Resistance of Deposited PVD Film to Wear and Dynamic Loads; Elsevier: Amsterdam, The Netherlands, 2017; Volume 13, pp. 702-709. [CrossRef]

10. Arroyo, J.M.; Diniz, A.E.; de Lima, M.S.F. Cemented Carbide Surface Modifications Using Laser Treatment and Its Effects on Hard Coating Adhesion; Elsevier: Amsterdam, The Netherlands, 2010; Volume 204, pp. 2410-2416. [CrossRef]

11. Gibson, I.; Rosen, D.; Stucker, B. Additive Manufacturing Technologies; Springer: Berlin/Heidelberg, Germany, 2015. [CrossRef]

12. Bandyopadhyay, A.; Bose, S. Additive Manufacturing; CRC Press: Boca Raton, FL, USA, 2016.

13. Kumar, S. Process Chain Development for Additive Manufacturing of Cemented Carbide; Elsevier: Amsterdam, The Netherlands, 2018; Volume 34, pp. 121-130. [CrossRef]

14. Johnson, J.L.; Enneti, R.K. Preface to Special Issue on 3D Printing of Refractory Metals and Hard Materials; Elsevier: Amsterdam, The Netherlands, 2020; Volume 88. [CrossRef]

15. Venuvinod, P.K.; Ma, W. Rapid Prototyping; Springer: Berlin/Heidelberg, Germany, 2004; Chapters 2, 7, pp. 25-55, 245-277. [CrossRef]

16. Pacurar, R.; Pacurar, A. Applications of the Selective Laser Melting Technology in the Industrial and Medical Fields; IntechOpen Limited: Rijeka, Croatia, 2016; pp. 161-185. [CrossRef]

17. Association, E.P.M. Introduction to Additive Manufacturing Technology, 2nd ed.; European Powder Metallurgy Association: Shrewsbury, UK, 2017.

18. Sames, W.J.; List, F.A.; Pannala, S.; Dehoff, R.R.; Babu, S.S. The Metallurgy and Processing Science of Metal Additive Manufacturing; Taylor \& Francis: Oxford, UK, 2016; Volume 61, pp. 315-360. [CrossRef]

19. Zetková, I. Complexity of Metal Mechanical Components Production by 3D Printing; University of West Bohemia: Pilsen, Czechia, 2017; pp. 19-25.

20. Neikov, O.D. Handbook of Non-Ferrous Metal Powders; Elsevier: Amsterdam, The Netherlands, 2009; pp. 65-399.

21. Uhlmann, E.; Bergmann, A.; Gridin, W. Investigation on Additive Manufacturing of Tungsten Carbide-Cobalt by Selective Laser Melting; Elsevier: Amsterdam, The Netherlands, 2015; Volume 35, pp. 8-15. [CrossRef]

22. Kruth, J.P.; Levy, G.; Klocke, F.; Childs, T. Consolidation Phenomena in Laser and Powder-Bed Based Layered Manufacturing; Elsevier: Amsterdam, The Netherlands, 2007; Volume 56, pp. 730-759. [CrossRef]

23. Gu, D. Laser Additive Manufacturing of High-Performance Materials; Springer: Berlin/Heidelberg, Germany, 2015; ISBN 978-3-662-46088-7. [CrossRef]

24. Prashanth, K.; Scudino, S.; Maity, T.; Das, J.; Eckert, J. Is the energy density a reliable parameter for materials synthesis by selective laser melting? Mater. Res. Lett. 2017, 5, 386-390. [CrossRef]

25. Wang, X.C.; Laoui, T.; Bonse, J.; Kruth, J.P.; Lauwers, B.; Froyen, L. Direct Selective Laser Sintering of Hard Metal Powders: Experimental Study and Simulation; Springer: Berlin/Heidelberg, Germany, 2002; Volume 19, pp. 351-357. [CrossRef]

26. Gu, D.; Meiners, W. Microstructure Characteristics and Formation Mechanisms of In Situ WC Cemented Carbide Based Hardmetals Prepared by Selective Laser Melting; Elsevier: Amsterdam, The Netherlands, 2010; Volume 527, pp. 7585-7592. [CrossRef]

27. Iveković, A.; Omidvari, N.; Vrancken, B.; Lietaert, K.; Thijs, L.; Vanmeensel, K.; Vleugels, J.; Kruth, J.P. Selective laser Melting of Tungsten and Tungsten Alloys; Elsevier: Amsterdam, The Netherlands, 2018; Volume 72, pp. 27-32. [CrossRef]

28. Zhou, X.; Liu, X.; Zhang, D.; Shen, Z.; Liu, W. Balling Phenomena in Selective Laser Melted Tungsten; Elsevier: Amsterdam, The Netherlands, 2015; Volume 222, pp. 33-42. [CrossRef]

29. Khmyrov, R.; Safronov, V.; Gusarov, A. Obtaining Crack-Free WC-Co Alloys by Selective Laser Melting; Elsevier: Amsterdam, The Netherlands, 2016; Volume 83, pp. 874-881. [CrossRef]

30. Maeda, K.; Childs, T. Laser Sintering (SLS) of Hard Metal Powders for Abrasion Resistant Coatings; Elsevier: Amsterdam, The Netherlands, 2004; Volume 149, pp. 609-615. [CrossRef]

31. Kumar, S. Manufacturing of WC-Co Moulds Using SLS Machine; Elsevier: Amsterdam, The Netherlands, 2009; Volume 209, pp. 3840-3848. [CrossRef]

32. Domashenkov, A.; Borbély, A.; Smurov, I. Structural Modifications of WC/Co Nanophased and Conventional Powders Processed by Selective Laser Melting; Taylor \& Francis: Oxford, UK, 2016; Volume 32, pp. 93-100. [CrossRef] 
33. Torralba, J. Improvement of Mechanical and Physical Properties in Powder Metallurgy; Elsevier: Amsterdam, The Netherlands, 2014; Volume 3, pp. 281-294. [CrossRef]

34. Heaney, D.; Binet, C. Hot Isostatic Pressing (HIP) of Metal Injection Molding (MIM); Woodhead Publishing: Sawston, UK, 2019; pp. 195-202. [CrossRef]

35. Bhatti, A.; Farries, P. Preparation of Long-Fiber-Reinforced Dense Glass and Ceramic Matrix Composites; Elsevier: Amsterdam, The Netherlands, 2000; Volume 4, pp. 645-667. [CrossRef]

36. Bricín, D.; Kř́̌̌z, A. Assessment of Usability of WC-Co Powder Mixtures for SLM. Manuf. Technol. 2020, 18, 719-726. [CrossRef]

37. Bricín, D.; Kř́iž, A. Comparison of the effect of the applied energy on the properties of prtotypes made from different types of powder mixtures. MM Sci. J. 2020, 2020, 3800-3805. [CrossRef]

38. International Organization for Standardization. ISO 4490:2014 Metallic Powders-Determination of Flow Rate by Means of a Calibrated Funnel (Hall Flowmeter); International Organization for Standardization: Geneva, Switzerland, 2014.

39. Kozior, T.; Bochnia, J. The influence of printing orientation on surface texture parameters in powder bed fusion technology with 316L steek. Micromachines 2020, 11, 639. [CrossRef] [PubMed]

40. Kozior, T.; Bochnia, J.; Zmarzły, P.; Gogolewski, D.; Mathia, T.G. Waviness of freeform surface characterizations from austenitic stainless steel (316L) manufactured by 3D printing-selective laser melting (SLM) technology. Materials 2020, 13, 4372. [CrossRef] [PubMed]

41. Khorasani, A.; Gibson, I.; Awan, U.S.; Ghaderi, A. The effect of SLM process parameters on density, hardness, tensile strength and surface quality of Ti-6Al-4V. Addit. Manuf. 2019, 25, 176-186. [CrossRef]

42. ASTM. ASTM B657-18 Standard Guide for Metallographic Identification of Microstructure in Cemented Carbides; ASTM International: West Conshohocken, PA, USA, 2000.

43. Bricín, D.; Špirit, Z.; Kř́žž, A. Metallographic Analysis of the Suitability of a WC-Co Powder Blend for Selective Laser Melting Technology; Trans Tech Publications Ltd.: Pfaffikon, Switzerland, 2018; Volume 919, pp. 3-9. [CrossRef]

44. Khairallah, S.A.; Anderson, A.T.; Rubenchik, A.; King, W.E. Laser Powder-Bed Fusion Additive Manufacturing: Physics of Complex Melt Flow and Formation Mechanisms of Pores, Spatter, and Denudation Zones; Elsevier: Amsterdam, The Netherlands, 2016; Volume 108, pp. 36-45. [CrossRef]

45. Zhong, Y.; Zhu, H.; Shaw, L.L.; Ramprasad, R. The Equilibrium Morphology of WC Particles-A Combined ab Initio and Experimental Study; Elsevier: Amsterdam, The Netherlands, 2011; Volume 59, pp. 3748-3757. [CrossRef]

46. Huo, S.; Qian, M.; Schaffer, G.; Crossin, E. Aluminium Powder Metallurgy; Woodhead Publishing: Sawston, UK, 2011; pp. 655-701. [CrossRef]

Publisher's Note: MDPI stays neutral with regard to jurisdictional claims in published maps and institutional affiliations.

(C) 2020 by the authors. Licensee MDPI, Basel, Switzerland. This article is an open access article distributed under the terms and conditions of the Creative Commons Attribution (CC BY) license (http://creativecommons.org/licenses/by/4.0/). 